\title{
Synthesis and Spectral Studies on Substituted Metal (II)-Tetra-1-(Thiophene-2-yl)methanimine Phthalocyanine Complexes
}

\author{
FASIULLA $^{\star 1}$ and YASHODA. M. P. ${ }^{1}$ \\ 'Department of Chemistry, Manipal Institute of Technology, MAHE, Manipal, \\ Udupi District, Karnataka, India. \\ *Corresponding author E-mail: fasiulla1976@gmail.com \\ http://dx.doi.org/10.13005/ojc/340344
}

(Received: March 08, 2018; Accepted: April 23, 2018)

\begin{abstract}
The synthesis, characterization of symmetrically substituted transition metal (II)-tetra-1-(thiophene-2-yl) methaniminephthalocyanine complexes by condensation of tetraamino phthalocyanines with 2-thiophenecarboxaldehyde had been prepared. The structural and characterization of theblue colour tetra -1-(thiophene-2- yl )methanimine phthalocyanine complexesare elucidated by using a number of analytical techniques like FT-Infrared, UV-Vis spectroscopy, XRD, magnetic measurements and thermo-gravimetric analysis. The kinetic parameters and thermal decomposition of synthesized phthalocyanines complexes were calculated using thermo-gravimetric analytical data.
\end{abstract}

Keywords: Tetra-(thiophene-2-yl) methanimine, IR spectra, Magnetic measurements, X-ray powder diffraction, TGA.

\section{INTRODUCTION}

As the metal phthalocyanines were prominent as dyes and pigments, so the first and foremost interest was taken in them. Phthalocyanines are commercial blue-green coloured pigments too. The blue-green colour is the result of strong absorption in the Q-band, the visible region of the spectrum. The succeeded intensive research is aimed at proving into, how the produce of the phthalocyanines was used sensitizers in photodynamic therapy and other medical applications and phthalocyanine derivatives are known for their applications in the field of liquid crystals, semiconductor devices, electro-photography, molecular electronics, electro-catalytic reagents, and also in the field of opto-electronics, electronics, and photonics. Solubility and variedphysico-chemical properties related with metal phthalocyanines were primarily depended upon the central metal atom, as well as the molecule's peripheral position.

This is an Open Access article licensed under a Creative Commons Attribution-Non Commercial-Share Alike 4.0 International License (https://creativecommons.org/licenses/by-nc-sa/4.0/), which permits unrestricted Non Commercial use, distribution and reproduction in any medium, provided the original work is properly cited. 
In this paper we have discusses the synthesis, spectral, magnetic susceptibility on symmetrically substituted transition metal (II) tetra-(thiophene-2yl) methanimine phthalocyanines. The available procedure is relatively modified and used for the synthetic route in the literature. The substituted transition metal (II) tetra-1-(thiophene-2-yl) methanimine phthalocyanine complexes is given as per the scheme-1.

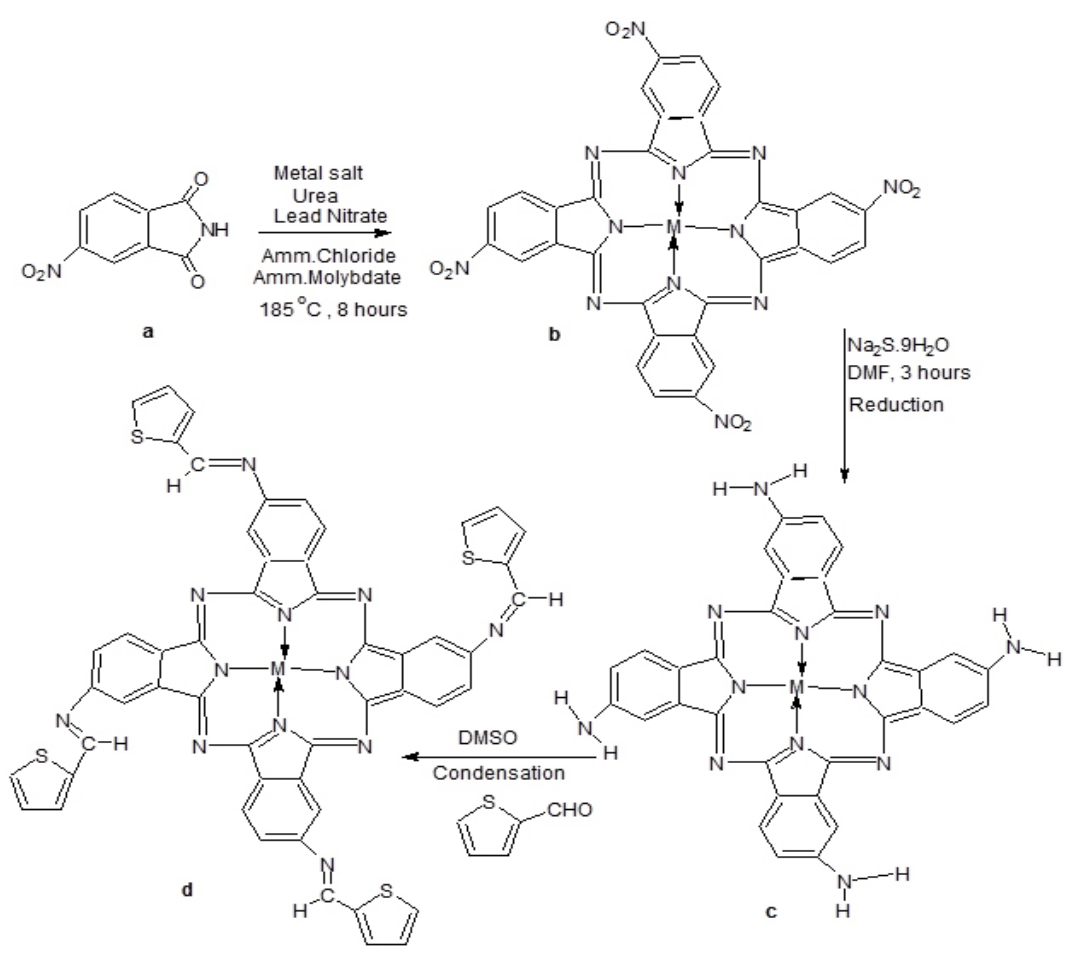

Scheme 1. Synthesis of 2, 9, 16, 23- tetra-1-(thiophene-2-yl) methanimine phthalocyanines. a. 4-Nitrophthalimide b. MPcON c. MPcOA d. MTTImPc

\section{EXPERIMENTAL}

4-Nitrophthalimide were procured from Sigma-Aldrich. All the other chemicals were purchase from different chemical supplier. The substituted transition metal (II) tetraamino phthalocyanines complexes condensed into iminophthalocyanine complexes with 2-thiophenecarboxaldehyde compounds as shown in scheme-1.

\section{Synthesis of Cobalt (II) tetra-1-(thiophene-2-yl) methaniminephthalocyaninecomplex}

4-nitro phthalamide (1 eq), cobalt sulphate (0.26 eq), and ammonium molybdate ( $0.5 \mathrm{eq}$ ) were taken with $12 \mathrm{~mL}$ of nitrobenzene, catalytic amount of ammonium molybdate and excess of urea in 3 necked round bottom flask. Reaction was kept for $120^{\circ} \mathrm{C}$ for first one hour and then gradually increased the temperature for every $30 \mathrm{~min}$., and finally, the mixture was heated to maintain $180^{\circ} \mathrm{C}$ for $5 \mathrm{~h}$ to form tetranitro cobalt phthalocyanine.
In the next step thus formed Tetra nitro cobalt phthalocyanine ( $1 \mathrm{~g}$ eq.) and ( $8 \mathrm{~g}$ eq.) of sodium sulfide were taken with dimethyl formamide in a $100 \mathrm{ml}$ round bottomed flask and kept for stirring at $80{ }^{\circ} \mathrm{C}$ for 24 hours. The mixture was poured into ice cold water and the precipitate was formed, filtered off and washed with hot water several times to remove unreacted sodium sulfide. Then it was given a $0.1 \mathrm{~N} \mathrm{HCl}$ wash several times followed by washing repeatedly with $0.1 \mathrm{~N} \mathrm{NaOH}$. Finally the precipitate is washed with hot $\mathrm{H}_{2} \mathrm{O}$, filtered and dry in oven.

The finely powdered cobalt(II) tetraamino phthalocyanine (M-PcTA) (6.32 g 0.01 mole) was dissolved in dimethyl sulfoxide with stoichiometric ratio of 2-thiphenecarboxaldehyde $(12.6 \mathrm{~mL}, 0.01$ mole). In the catalytic quantity of conc. $\mathrm{H}_{2} \mathrm{SO}_{4}$ the mixture got refluxed for 5 hours. Then mixture were poured in to an ice-cold water. The precipitate was washed with alcohol until several times to formed 
completely free from substituted aldehydes. The precipitate is washed with distilled hot water and dried in vacuum $\mathrm{P}_{2} \mathrm{O}_{5}$. Similar procedure is adopted to prepared the CuTTImPc, NiTTImPc, ZnTTImPc complexes.

\section{METHODS}

Elemental analysis was carried out at STIC, Kochi, Kerala, India. The Gouy magnetic balance was used to measure the magnetic susceptibility of tetra substituted metal (II) iminomethane phthalocyanines at room temperature. Mercury cobalt(II) tetrathiocynaide as calibrant used reference complex to calculate diamagnetic behavior. Shimadu UV-Visible spectrometer, UV-160A used for recording electronic absorption spectra. FT-IR spectral was used to identify the different functional groups in compounds. The diffraction patterns was recorded by using Phillip PW1710 XRD. Perkin Elmer thermal analyzer at a heating rate of $10 \% \mathrm{~min}$., both in the nitrogen atmosphere and air to calculate the TGA data.

\section{RESULTS AND DISCUSSION}

Tetra-1-(thiophene-2-yl) methanimine phthalocyanines complexes are synthesis by adopting simple modified procedure. The colour of the complexes is bluish green in nature. It is soluble in DMF, DMSO, conc. $\mathrm{H}_{2} \mathrm{SO}_{4}$, pyridineand partially soluble in ethanol. The percentage of carbon, hydrogen, nitrogen, sulphur are agreed with theoretical value indicating the purity of the synthesized complexes. The proposed structure of the synthesized Tetra-1-(thiophene-2-yl) methanimine phthalocyanines complexes are shown in scheme1and Figure 1.

\section{Electronic [UV-Visible]}

The concentration range at 1.0-1.5 X10-4 $\mathrm{M}$ in DMF, the electronic spectra of M-TTImPcs was recorded Fig. 2 and Table 1. The bluish color of the phthalocy anine compound observed due to a2ueg \& b2ueg transitions state. The corresponding parent metal phthalocyanines are lower than the all complexes shows in the wavelength range 721$734 \mathrm{~nm}$. In all the complexes Q-band was doubled by ranging 572-588 $\mathrm{nm}$. And the a1ueg transition state of the phthalocyanine moiety was attributed with the originated Q-band both the sharp intense B-band ranged 325- $332 \mathrm{~nm}$ and weak L-band ranged 211- $219 \mathrm{~nm}$ was observed forall the complexes these B-band and L-band may be accounted for C-band in the phthalocyanines moiety.

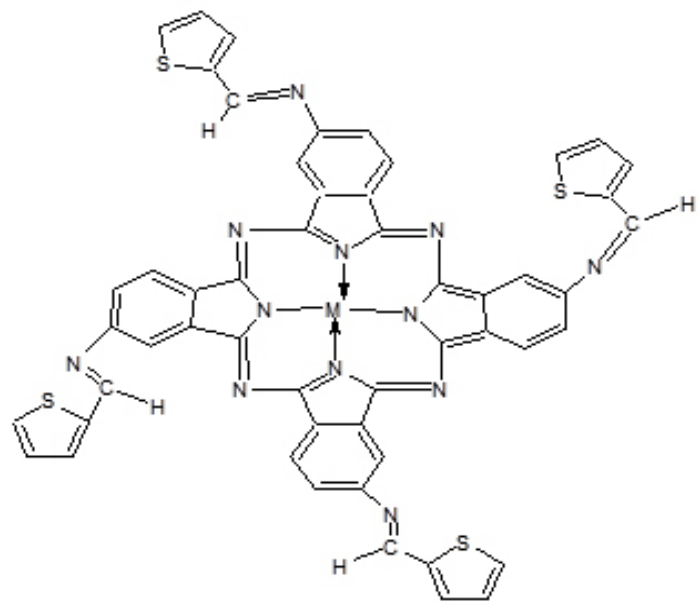

Fig. 1. Proposed structure of substituted metal (II) 2, 9 16, 23 -(thiophene-2-yl) methanimine phthalocyanine complexes. $\mathrm{M}=[$ Cobalt, Copper, Nickel, Zinc]salts

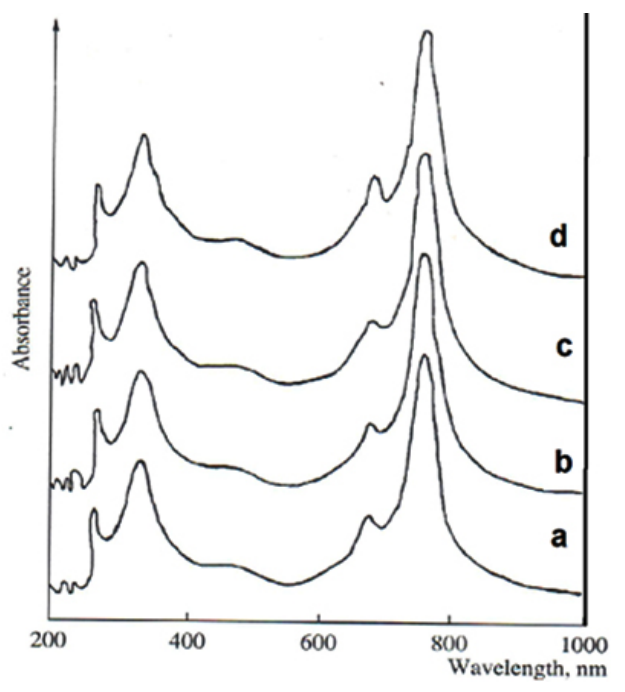

Fig. 2. Electronic Spectra of a) CoTTImPc, b) a) $\mathrm{Cu}$-TTImPc, c) Ni-TTImPc, d) Zn-TTImPc

\section{Infra-red}

Relevant Infra-red data was recorded by using $\mathrm{KBr}$ pellets, results are reported in Table 1, Fig. 3. An intense (sharp) peak in the range 1619- $1630 \mathrm{~cm}^{-1}$ is due to $\mathrm{C}=\mathrm{N}$ of imine group. $\mathrm{C}-\mathrm{N}$ Ar. stretching vibration peak in the range of 1365- $1388 \mathrm{~cm}^{-1}$. The C-S-C asy. stretching vibration 
is assigned in the range of $768-643 \mathrm{~cm}^{-1}$ and C-S-C sym. stretching vibrations is observed in the range 1058- $1118 \mathrm{~cm}^{-1}$. The peak is assigned in the range 3424- $3450 \mathrm{~cm}^{-1}$ hydrogen bonding due to nitrogen

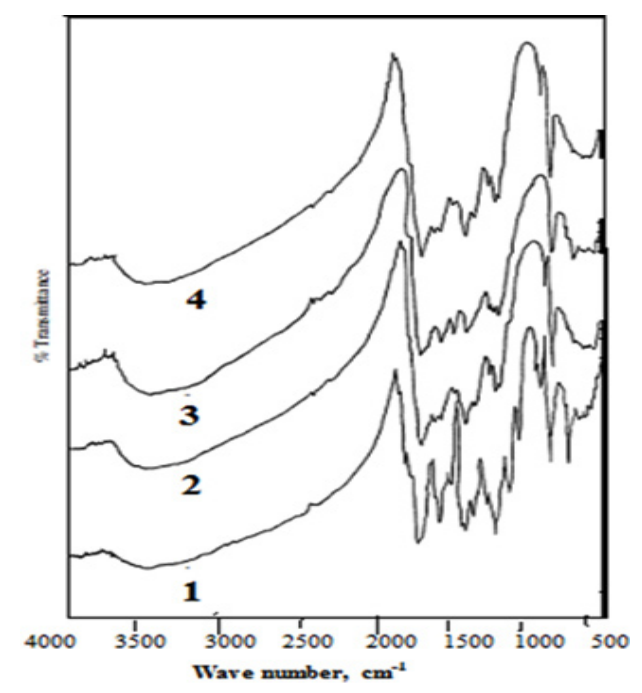

Fig. 3. IR spectra of 1) Co-TTImPc, 2)Cu-TTImPc,3) Ni-TTImPc, 4) Zn-TTImPc atom in the phthalocyanines moiety and hydrogen atom in the $\mathrm{KBr}$ pellets. A weak signal $\mathrm{C}-\mathrm{H}$ vibrational stretching at the periphery of the phthalocyanines moiety is assigned at the range $2325-2366 \mathrm{~cm}^{-1}$. The range of $551-590 \mathrm{~cm}^{-1}$ are attributed to various characteristic skeletal peak of the phthalocyanines molecule

\section{Magnetic susceptibility}

At an ambient temperature, magnetic measurement dataare presented in Table 2. As per the magnetic measurement studies CUTTImPc, CoTTImPc are behaves as paramagnetic complexes and like wise NiTTImPc, ZnTTImPc are diamagnetic complexes in nature. The magnetic moment measured are higher the spin value in CUTTImPc and CoTTImPc compare to corresponding unpaired electron.By the crystallographic studies substituted phthalocyanines different metal are isomerphous and have sq. planar structure with D4h symmetry in Figure 4.

Table 1: Electronic and IR spectra data

\begin{tabular}{|c|c|c|c|c|}
\hline $\begin{array}{l}\text { Complex Name } \\
\text { Yield (\%) } \\
\text { (Colour) }\end{array}$ & $\begin{array}{c}\text { Molecular } \\
\text { formula } \\
\text { (Molecular weight) }\end{array}$ & $\begin{array}{l}\text { UV-visible } \\
\text { absorption } \\
\lambda \mathrm{nm}(\log \in)\end{array}$ & $\begin{array}{l}\text { Elemental analysis (\%) } \\
\text { found (calcd) }\end{array}$ & $\begin{array}{l}\text { IR-Spectral } \\
\text { Data }\left(\mathrm{cm}^{-1}\right)\end{array}$ \\
\hline $\begin{array}{l}\text { Co-TTImPc } \\
-85 \% \\
\text { (Dark green) }\end{array}$ & $\begin{array}{c}\mathrm{C}_{52} \mathrm{H}_{28} \mathrm{~N}_{12} \mathrm{~S}_{4} \mathrm{Co} \\
-1006.93\end{array}$ & $\begin{array}{l}215(4.90) \\
264(4.79) \\
328(5.39) \\
588(5.07) \\
734(5.11)\end{array}$ & $\begin{array}{c}\text { C, 61.90; (61.97) } \\
\text { H, 2.68; (2.78) } \\
\text { N, 16.54; (16.68) } \\
\text { S, 12.67;(12.71) } \\
\text { Co }(5.85)\end{array}$ & $\begin{array}{c}590,768,1058, \\
1124,1378,1619, \\
1709,2366,3450 .\end{array}$ \\
\hline $\begin{array}{l}\text { Cu-TTImPc } \\
-84 \% \\
\text { (Dark green) }\end{array}$ & $\begin{array}{c}\mathrm{C}_{52} \mathrm{H}_{28} \mathrm{~N}_{12} \mathrm{~S}_{4} \mathrm{Cu} \\
-1011.55\end{array}$ & $\begin{array}{l}211(4.87) \\
259(4.76) \\
332(5.40) \\
577(5.01) \\
732(5.12)\end{array}$ & $\begin{array}{c}\text { C, 61.54; (61.68) } \\
\text { H, 2.67; (2.76) } \\
\text { N, 16.53; (16.60) } \\
\text { S, 12.60;(12.65) } \\
\text { Cu }(6.28)\end{array}$ & $\begin{array}{c}582,670,1090, \\
1385,1630,1714, \\
2365,3442 .\end{array}$ \\
\hline $\begin{array}{l}\text { Ni-TTImPc } \\
-83 \% \\
\text { (Dark green) }\end{array}$ & $\begin{array}{c}\mathrm{C}_{52} \mathrm{H}_{28} \mathrm{~N}_{12} \mathrm{~S}_{4} \mathrm{Ni} \\
-1006.69\end{array}$ & $\begin{array}{l}214(4.78) \\
262(4.59) \\
325(5.02) \\
580(4.52) \\
724(4.59)\end{array}$ & $\begin{array}{c}\mathrm{C}, 61.91 ;(61.98) \\
\text { H, 2.70; (2.78) } \\
\text { N, 16.62; (16.68) } \\
\text { S, 12.68;(12.71) } \\
\text { Ni (5.82) }\end{array}$ & $\begin{array}{c}573,663,1112, \\
1365,1402,1626, \\
2221,2360,3424 .\end{array}$ \\
\hline $\begin{array}{l}\text { Zn-TTImPc } \\
-80 \% \\
\text { (Dark green) }\end{array}$ & $\begin{array}{l}\mathrm{C}_{52} \mathrm{H}_{28} \mathrm{~N}_{12} \mathrm{~S}_{4} \mathrm{Zn} \\
-1013.39\end{array}$ & $\begin{array}{l}219(5.21) \\
251(5.40) \\
330(5.47) \\
572(5.39) \\
721(5.04)\end{array}$ & $\begin{array}{c}\text { C, 61.54; (61.57) } \\
\text { H, 2.71; (2.76) } \\
\text { N, 16.52; (16.57) } \\
\text { S, 12.60;(12.63) } \\
\text { Zn }(6.45)\end{array}$ & $\begin{array}{c}551,643,1118, \\
1388,1627,2325, \\
2362,3441 .\end{array}$ \\
\hline
\end{tabular}




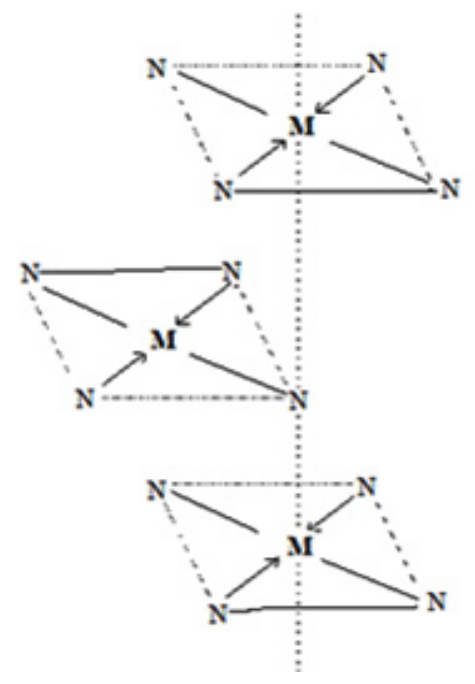

Fig. 4. Mechanism of molecular stacking of metal phthalocyanine crystal, (M = Cu(II), $\mathrm{Co}$ ( II), $\mathrm{Ni}(\mathrm{II})$, $\mathrm{Zn}(\mathrm{II}) \mathrm{N}=$ azamethaine atom

\section{Powder XRD}

The range of $2^{\circ}$ angles were used take the powder XRD pattern of MTTImPcs. Angles 6-70 showedthe relatively very poor crystalline peaks Table 2. The pattern is observed to same as the unsubstituted phthalocyanine complexes except the peak with diffuse intensity. Because of the molecular periphery there was a broadening in pattern. This broadening gives the hindrance due to effective stacking of the molecule. It is poor crystalline in nature phthalocyanine complexes.

\section{Thermogravimetric and kinetic studies}

In the Table 3, the thermo gravimetric analysis data are reported. In the two steps, an occurrence of the decomposition of above complexes was found. The first step indicated all the subsitutent groups in phthalocyanines are degradation in air at the temperature 250 to $350^{\circ} \mathrm{C}$. In the second step degradation steps all the complexes observed the major mass loss at $350-600^{\circ} \mathrm{C}$. After thermal decomposition the residue remains as a metal oxide. In nitrogen atmosphere the substituted metal imino phthalocyanines complexes are very slow thermal decomposition. The $64 \%$ that was decomposed at $700{ }^{\circ} \mathrm{C}$ complex CoTTImPc, while for CuTTImPcmet with $58 \%$ mass loss , NiTTImPc with $55 \%$ and $\mathrm{ZnTTImPc}$ with $48 \%$ mass loss. In air the complexes are shows the higher stability like CoTTImPc > CuTTImPc > NiTTImPc > ZnTTImPc. Boride's method was used to evaluate the kinetic and thermodynamic parameters. and all the degradation

Table 2: XRD and magnetic susceptibility measurements

\begin{tabular}{|c|c|c|c|c|c|}
\hline Complex Name & $2 q$ angle $(\mathrm{d} \AA)$ & $\begin{array}{c}\text { (Relative } \\
\text { Intensity) (\%) }\end{array}$ & $\begin{array}{l}\text { Field strength } \\
\text { (KGauss) }\end{array}$ & $\begin{array}{c}\text { Magnetic } \\
\text { measurement } \\
\chi \mathrm{m} \times 10-6 \mathrm{cgs} \\
\text { units }\end{array}$ & $\mu \operatorname{eff}(B . M)$ \\
\hline & $9.32(10.32)$ & 100 & 2.2 & 3265.87 & 2.73 \\
\hline \multirow[t]{5}{*}{ CoTTImPc } & $28.81(4.07)$ & 91.36 & 2.66 & 3035.41 & 2.55 \\
\hline & $24.43(2.43)$ & 89.16 & 3.1 & 2838.16 & 2.41 \\
\hline & & & 3.58 & 2713.64 & 2.34 \\
\hline & & & 4.01 & 2540.26 & 2.19 \\
\hline & $6.80(12.79)$ & 100 & 2.2 & 3145.62 & 2.69 \\
\hline \multirow[t]{5}{*}{ CuTTImPc } & $8.58(10.82)$ & 92.27 & 2.66 & 3003.16 & 2.57 \\
\hline & $29.92(3.47)$ & 90.45 & 3.1 & 2851.79 & 2.43 \\
\hline & & & 3.58 & 2702.61 & 2.31 \\
\hline & & & 4.01 & 2514.19 & 2.17 \\
\hline & 6.89 (14.72) & 100 & 2.66 & & \\
\hline \multirow[t]{3}{*}{ NiTTImPc } & $8.82(10.17)$ & 89.69 & & -747.51 & --- \\
\hline & $27.26(3.47)$ & 84.24 & & & \\
\hline & $6.88(14.57)$ & 100 & 2.66 & & \\
\hline \multirow[t]{2}{*}{ ZnTTImPc } & $8.79(11.18)$ & 92.78 & & -1041.02 & --- \\
\hline & $25.94(2.83)$ & 94.15 & & & \\
\hline
\end{tabular}


steps are exothermic in nature as per DTA results The loss of periphery-tetra-1-(thiophene-2-yl) methanimine phthalocyanine complexes by the energy of activation (Ea) between the range of 0.87-4.79 $\mathrm{KJ} / \mathrm{mole}$. The breaking of the main phthalocyanine complex ring takes place with the immediate removal of periphery substituents. By the negative entropies of the degradation, exothermic behavior of degradation was clearly indicated. Even there entropies are negative from -158.64 to -176.16 $\mathrm{KJ}$. It was clearly indicated decomposition that the removal of functional groups. By using standard equations enthalpy, entropy and free energy was computed in Table 4.

Table 3: Thermodyamic degradation pattern

\begin{tabular}{lcccc}
\hline & \multicolumn{4}{c}{ Weight Loss (\%) } \\
\hline Complexes Name & Decomposition $\left[{ }^{\circ} \mathrm{C}\right]$ & Found & Calcd & Fragmentation \\
\hline \multirow{2}{*}{ CoTTImPc } & $250-350$ & 28.84 & 30.04 & 4-Imino groups \\
& $350-600$ & 65.46 & 65.83 & Phthalocyanine moiety \\
CuTTImPc & $250-350$ & 28.82 & 30.15 & 4-Imino groups \\
& $350-600$ & 65.96 & 65.01 & Phthalocyanine moiety \\
NiTTImPc & $250-350$ & 28.79 & 30.19 & 4-Imino groups \\
& $350-600$ & 65.87 & 65.19 & Phthalocyanine moiety \\
ZnTTImPc & $250-350$ & 28.64 & 30.1 & 4-Imino groups \\
& $350-600$ & 65.52 & 65.11 & Phthalocyanine moiety \\
\hline
\end{tabular}

Table 4: Kinetic and thermodynamic data in inert atmosphere and air

\begin{tabular}{|c|c|c|c|c|c|c|}
\hline Complexes Name & & $\begin{array}{c}\text { Ea } \\
\left(\mathrm{kJ} \mathrm{mole}^{-1}\right)\end{array}$ & $\begin{array}{l}\text { Frequency factor. } \\
\qquad\left(\operatorname{InA} \min ^{-1}\right)\end{array}$ & $\begin{array}{l}\text { Enthalpy } \\
\left(\mathrm{kJmole}^{-1}\right)\end{array}$ & $\begin{array}{c}\text { Entropy } \\
\left(\mathrm{kJ} \mathrm{mole}^{-1}\right)\end{array}$ & $\begin{array}{r}\text { Free energy } \\
\left(\mathrm{kJ} \mathrm{mole}^{-1}\right)\end{array}$ \\
\hline \multirow[t]{4}{*}{ CoTTImPc } & I & 4.79 & 5.2 & -1.69 & -164.03 & 62.45 \\
\hline & & -0.75 & -3.03 & $(-1.27)$ & $(-160.10)$ & -61.56 \\
\hline & II & 4.46 & 4.39 & 2.74 & -152.07 & 81.59 \\
\hline & & -1.51 & -5.47 & $(-1.41)$ & $(-149.67)$ & -79.52 \\
\hline \multirow[t]{4}{*}{ CuTTImPc } & 1 & 0.87 & 6.34 & -1.37 & -176.16 & 74.86 \\
\hline & & -0.68 & -3.35 & $(-1.14)$ & $(-174.11)$ & -74.69 \\
\hline & II & 4.64 & 7.39 & 2.79 & -143.82 & 79.42 \\
\hline & & -1.25 & -4.65 & $(-1.32)$ & $(-141.89)$ & -77.24 \\
\hline \multirow[t]{4}{*}{ NiTTImPc } & I & 1.43 & 5.2 & -1.21 & -158.64 & 72.79 \\
\hline & & -0.71 & -2.22 & $(-0.74)$ & $(-157.49)$ & -70.48 \\
\hline & II & 5.86 & 4.42 & -0.85 & -149.75 & 81.66 \\
\hline & & -1.53 & -4.82 & $(-0.83)$ & $(-143.64)$ & -80.23 \\
\hline \multirow[t]{4}{*}{ ZnTTImPc } & I & 1.92 & 3.36 & -0.95 & -175.84 & 75.42 \\
\hline & & -0.63 & -2.43 & $(-1.50)$ & $(-173.41)$ & -74.75 \\
\hline & II & 8.53 & 7.78 & 2.74 & -142.51 & 82.48 \\
\hline & & -5.57 & -6.46 & $(-1.53)$ & $(-140.67)$ & -80.92 \\
\hline
\end{tabular}

(I \& II indicated as degradation in nitrogen atmosphere)

\section{CONCLUSION}

Synthesis of substutited metal phthalocyanines was adopted by simple modified method. The Copper and Cobalt phthalocyanine complexes are paramagnetic in behavior measured by magnetic susceptibility studies. The variation of magnetic moments with magnetic field 
[2.20 to $4.01 \mathrm{KG}$ ] clearly indicated the presence of intermolecular co-operative effect in the compound. These complexes are poor in crystanillity in nature. The stability of the complexes in gravimetric analysis in an inert atmosphere like CuTTImPc $>$ CoTTImPc > NiTTImPc > ZnTTImP.

\section{ACKNOWLEDGMENT}

I sincerely thank to my guide KRV and HOD of chemistry, Manipal Institute of Technology, Manipal. Academy of Higher Education (MAHE), Manipal, Udupi for providing the laboratory facilities.

\section{REFERENCES}

1. Achar, B.N.; Fohlen.; Parker, G.M.; Keshavayya, J.; Polyhedron., 1989, 6(6), 1463.

2. Achar, George, M.; Fohlen; Parker, J. A. united state patent., 1984, 45(4), 268.

3. Arthur I. Vogel, Quantitative Iorganic Analysis, 3rd Ed., Longmans Publishers, London. 1964.

4. Bartoli, J.F.; Brigoud, P.; Battioni,P.; Mansuy, D.; J. Chem. Soc, Chem. Commun.,1994, 440.

5. Broido, A. J. Polym. Sci., Part A-2.1969, 71761.

6. Dandridge, A.E.; Drescher, H.A.; J. Thomas, J.(To Scottish Dyes Ltd) British patent., 1929, 822, 169.

7. Dent, C.E.; Linstead, R. P.; Lowe, A. R. J. Chem. Soc., 1934, 1033.

8. Eltis, R.B.; Lyons, J. E. Coord., Chem. Rev. 1990, 105.

9. Grinstaff, M.W.; Hill, M.G., Labinger, I.; Gray, H.B. Science.,1994, 264, 311.

10. Harsans, M.C.; Guisinger, N.P.; Lyding, J. W. Nanotechnology., 2000, 11, 70.

11. Jasinski, R., Nature.,1964, 201, 1212.

12. Kobel,W.; Hanack, M. Inorg. chem., 1968, 25, 103.

13. Leznoff, C.C.; Lever, A.B.P. Phthalocyanines, properties and applications: $\mathrm{VCH}$ publications, Inc., New York., 1989, 1, 173.

14. Manjunatha, N.; Imadadulla, M.; Lokesh, K.S.; Reddy. K. R.V. Dyes and Pigments., 2018, 153, 213- 224.

15. Moinuddin Khan, M. H.; Fasiulla.;Venugopala Reddy, K.R.; Harish, M. N. K.; Keshavayya, J.
J. Coord. Chem., 2007, 60(12), 1255-1267

16. Paquette, B.; Ali, H.; Van Lier, E. J. J. Chim. Phys. Phys-Chim. Biol.,1991, 88, 1113.

17. Priola, S.A.; A. Raines,A.; Caughey, W.S. Science., 2000, 287, 1503.

18. Selwood, P. Magnetochemistry, New York, Interscience., 1956.

19. Scblewein, D.; Karmann, E.; Ockermann, T.; Yanagi, H.; Electrochim. Acta., 2000, 45, 4697.

20. Sheldon, R.A. Metalloporphyrin catalytic oxidation. Marcel Decker, New York, 1194.

21. Somashakarappa, M.P.; Keshavayya. J. Spectrochemica Act. Part-A., 2003, 59, 767.

22. Somashekarappa, M P.; Venugopala Reddy, K R.; Harish, M.N.K.; Keshavayya, J. J. Molecular Structure., 2005, 753, 190-194.

23. Somashekarappa, M. P.; Keshavayya, J. Synth. React. Inorg. Met-org. chem., 1999, 29(5), 767.

24. Somashekarappa, M.P.; Keshavayya, J. J. Soudi. Chem. Soc.,1999, 3(2), 113.

25. Somashekarappa, M.P.; Venugopala Reddy, K.R.; Harish, M.N.K.; Keshavayya, J. J. T. R. Chem., 2004, 11(1), 1.

26. Venugopala Reddy, K R.; Keshavayya, J. Synth React Inorg Met-Org Chem., 2002, 32(7), 1235-1244.

27. Venugopala Reddy, K R.; Keshavayya, J. Turk J Chem., 2002, 26(4), 573.

28. Whorle, D. Adv. polym. Sci. Review Article., 1983, 50. 